\title{
SOME PROBLEMS RELATED TO THE EXPLOITATION OF AUTOMATED CONTAINER TERMINALS
}

\author{
Yana Gancheva \\ Nikola Vaptsarov Naval Academy (Bulgaria)
}

\begin{abstract}
Automation is considered as the basis for the introduction of the fourth industrial revolution in ports and for the implementation of a number of innovations. Often the actual results of container terminal automation do not match the expectations of terminal operators. Through the application of scientific methods of investigation - monitoring, comparative analysis, analysis and synthesis of existing publications on the subject - some problematic issues have been established, such as the lack of common standards, pressure by trade unions, processing of exceptions, etc., calling into question the implementation of any good automated terminal project. The synergistic approach in the modeling, construction and exploitation of automated container terminals leads to the conclusion that, on one hand, a solution to the above issues should be sought in the cooperation between all port stakeholders (automation system manufacturers, software developers, terminal and logistics operators, carriers). On the other hand, the competitiveness of automated container terminals depends on the skills of the port specialists. They must be prepared for the monitoring, analysis and management of automated systems, they must be adequately qualified for the integration of systems and for the processing of exceptions, they must be able to foresee the consequences of each of their actions for the whole system.

Keywords: automated container terminals; lack of standardization; job cuts; exception handling
\end{abstract}

\section{Introduction}

Automation is one of the largest technological trends of today's generation, which is a constant source of debates and analysis. It also determines the innovations implemented by the ports continuously searching for ways to handle more cargo, to increase efficiency and quality, and to reduce emissions (Schwerdtfeger 2020).

At first glance, container terminals look like ideal places that can be automated - the physical environment is structured and predictable, and many operations are repetitive and clear. They generate a huge amount of data that is easy to collect 
and process. In addition, automation contributes not only to greater savings, but also to increasing the productivity and safety of ports and companies operating therein. Notwithstanding the foregoing, it has been established that automation in port is carried out slower than in sectors of comparable complexity, such as mining, warehousing, car manufacture, etc.

Studies by industry leaders show that, in fact, the operation of most automated ports is not more efficient. Safety is significantly improved, the number of manmade disturbances is reduced, but work is becoming yet more unpredictable. Experts even believe that these ports, especially fully automated ones, are generally less productive than the conventional ones, and the return on investment at some automated terminals is below $1 \%$ at an industry rate of about $8 \%$ (Chu et al. 2018).

Based on a study and analysis of the opinions of port experts, economic analysts and consultants, the paper research aims to outline some serious problems that still represent obstacles for the widespread introduction of automation in container terminals.

The paper defines the following two tasks in order to accomplish its objective:

1. to reveal the factors determining the automation as a trend in the development of the container terminals;

2. to point out some negative effects suffered by ports as a result of the introduction of automation which at the same time unite stakeholders in the port sector to search for ways for solving them.

The research in the paper is limited to examining the consequences of automation related to: the lack of standardization of container equipment and IT systems, the impact on employment, the occurrence of risks resulting from the uncertain increase of productivity, and the need for processing exceptions.

\section{Analysis of the trends for automation of container terminals}

The drive for automation is commercial - carriers exercise tremendous pressure on ports to accept yet larger ships. Therefore, sometimes terminals have to handle more than 10,000 TEUs intended for one ship within 24 hours. The benefits of mega-container vessels are also unequally distributed. Shipping lines benefit from economies of scale, while ports "pay" most of the price. The 2015 White Paper of the International Transport Forum (ITF) estimates that megaships would add up to $\$ 400$ million a year to the operating and capital costs of terminals, one-third of which are for equipment, one-third for dredging and the rest - for port infrastructure.

In 2018 McKinsey estimated that ports have globally invested $\$ 10$ billion in the automation of their terminals, which exceeded all expectations. Given that shipyards receive orders for new mega-ships, most probably the productivity of the terminals and the expectations of the shipping lines would diverge, if there is no significant intervention. The analysis of a study on the productivity of the terminals 
for the first half of 2018 and 2019 among seven of the ten largest container operators shows that urgent intervention in the capacity and productivity of the terminals is required. This also explains the fact that a number of terminal owners and operators choose to automate a lot of the container site functions. However, the report has one significant drawback - no illustrative statistics are used to make conclusions, the general opinion being reflected instead. In fact, terminal operators state that the results of semi-automation are "below expectations" and those of full automation "far below expectations" (Saanen 2020).

The Port Equipment Manufacturers Association (PEMA) summarizes the conditions crucial for the successful implementation of automation in the container terminals as follows:

- adapting the design of the terminal to the prevailing conditions (labor costs, etc.);

- taking the necessary measures so that the new terminal applies the latest technology in order to be competitive in the future;

- making no major changes requiring additional tests which may cause delays or cost overruns;

- clear definition of operating conditions, such as the presence of restrictions on the type of containers or vehicles, taking into account working conditions and others;

- confirmation of the design and number of the necessary lifting gear and cranes by using the modelling technology;

- introduction of automation is not only a project for the implementation of technologies but also requires a complete change of most operational processes and practices of the terminal, as well as a change of activities related to personnel management;

- deployment of automation requires integration of multiple IT systems, which means that all vendors in the process must have a common understanding of how the final solution will work. ${ }^{1}$

Table 1 presents the main advantages and disadvantages of terminal automation for the terminal operators ${ }^{2}$.

Table 1. Advantages and disadvantages of container terminal automation

\begin{tabular}{|l|l|}
\hline Advantages & Disadvantages \\
\hline - reducing operating costs & - high capital investment costs \\
\hline - saving time and resources & - pressure by trade unions due to job cuts \\
\hline - increasing throughput & - cyber security risks \\
\hline $\begin{array}{l}\text { - improving process stability and service } \\
\text { reliability }\end{array}$ & $\begin{array}{l}\text { - high costs for software maintenance and } \\
\text { system upgrades }\end{array}$ \\
\hline - better emission control in ports & - no guaranteed increase of productivity \\
\hline
\end{tabular}


The analysis of the data in Table 1 shows that along with the advantages that automation provides to container terminals, it poses almost as many problems of financial, social, investment, cyber and operational nature.

In July 2019, the rating agency Moody's published an investment assessment report and stressed that automated container terminals offered "competitive advantages" and predicted that more of them would be built in the next decade ${ }^{3}$. As of mid-2019, 49 container terminals worldwide were fully or partially automated. They represented $9.1 \%$ of all main terminals and $12.6 \%$ as an area in hectares. The results of the comparison of the average size of a conventional container terminal, a fully and semi-automated container terminal are shown in fig. 1 and give an idea of the scale of automation of the terminals ${ }^{4}$.

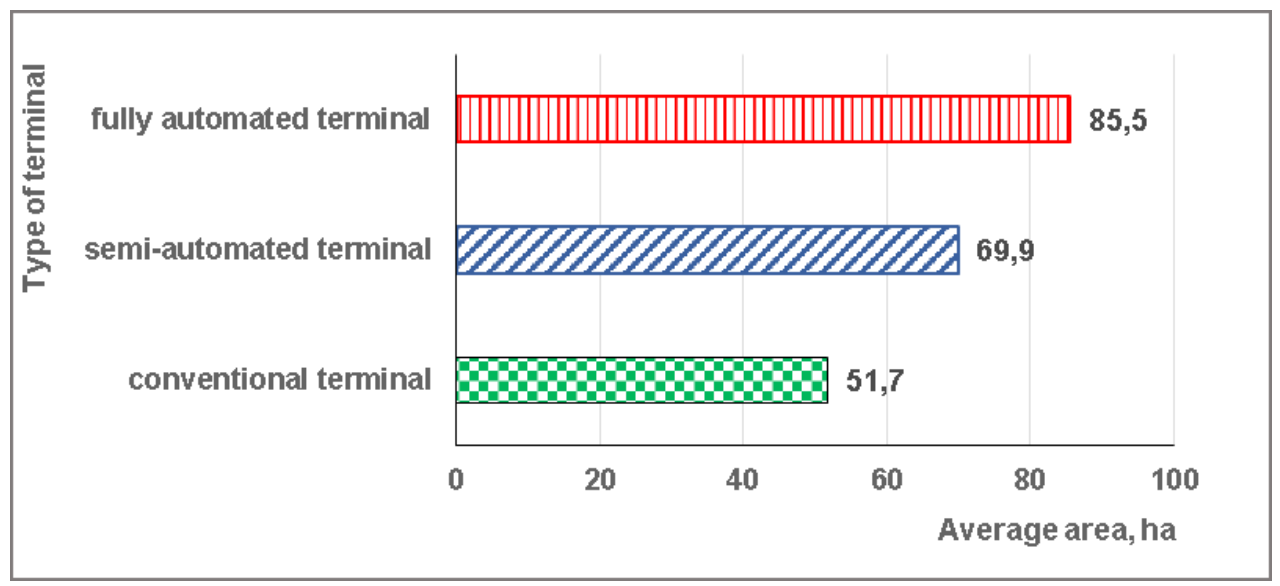

Figure 1. Average area according to the type of the container terminal

From Fig. 1 one can trace the tendency that container terminals with an average area of 52 hectares retain their conventionality. Interest in the automation of processes is observed in container terminals with an average area of 70 hectares, and fully automated terminals are built in an area of 85 hectares.

Recent market research shows that the industry continues to grow rapidly. According to B2B Research Group Marketsandmarkets, the market share of semi- and fully automated terminals has reached $\$ 9.09$ billion. It is estimated that by 2023 it will have grown by $20 \%$ and reached $\$ 10.89$ billion. Partial automation works are forecast to increase by $4.4 \%$ in the following years, which means that even if full automation is not implemented, the ports will continue to offer automated solutions. The observed trend is explained by the large number of "green projects" in the Asia-Pacific region, which require a large volume of new automated port facilities. On the other hand, there is increased demand of larger container vessels and intensified competition 
among container terminals. Currently, the Asia-Pacific region dominates the market of automated container terminals, followed by Europe and North America. This is due to the efforts of the parties in the sector, mainly China, Japan, India and Australia, to improve the infrastructure of their ports with the help of automation ${ }^{5}$. (Schwerdtfeger 2020) From the above, it is obvious that automation will be an indispensable part of the development of the ports over the next few years, as those taking steps nowadays will be competitive in the future. There are a number of problematic issues though, without the solution of which the benefits of automation could not be fully utilized. Some of these are presented in the second task of this paper.

\section{Main problems related to the automation of container terminals}

To solve the second task, an analysis has been conducted of the opinions of port experts and terminal operators, reports of rating companies and economic analysts, which warn that high capital investments, uncertain increase in productivity, potential interruption of current operations, position of trade unions, lack of standardization, and others pose a risk to automation projects ${ }^{6}$.

The following are some of the problematic issues for which a solution is being sought:

\section{Lack of standardization}

Different equipment and IT systems, which build automated terminals, cannot exchange meaningful and effective information, i.e. they are provided by different suppliers. Suppliers prefer to promote their own products and use their own technical standards instead of working on industry-friendly solutions. According to the executive director of APT Terminals, Tim Smith, the lack of standardization hinders the progress of container terminals. It is also a reason for ports to slow down their development. It turns out that the full automation of a large container terminal is an extremely complex challenge. Experts say that today terminal automation projects are predominantly unique and highly personalized individual solutions. (Shen 2019)

The above explains the meaning of standardization - to enable terminals to take advantage of the benefits of automation faster. In order to accelerate its implementation, the project start-up times must be radically shortened, the maintenance of the extremely complex automated systems must be simplified; it must be possible to copy and apply standardized solutions to one or another implementation instead of rediscovering the "wheel" over and over again for each terminal. But it is not just about standardizing the protocols through which different systems operate or the levels of safety and reliability that should be expected from automated container handling equipment. It also covers internal processes and key issues, such as how to define the term "number of movements per hour". Even these basic concepts need to be standardized to enable the measurement and sequential tracking of the data on the efficiency of automated terminals, as well as the evaluation and comparison of this data as part of the continuous optimization of the processes (Kaunonen 2018). 
To address this significant problem, a number of major carriers join the Digital Container Shipping Association, which aims to make the digital standardization in container shipping possible. The organization has been recruiting members among the terminal operators so far, but in the future, it will be open to more participants in the logistics chain. Cooperation between terminal operators and industry associations is the first step towards standardization in the sector in order to achieve more efficient and reliable automation. However, to benefit from automation and quickly achieve operational safety and improved efficiency, the joint efforts of the entire port industry are required.

Social tension due to job cuts and transformations

The automation of container terminals has led to a series of strikes by port workers fearing that hundreds of them will lose their jobs. On this occasion, in 2019 Prism Economics and Analysis conducted a study commissioned by the International Union of Port and Warehouse Workers in Canada. It identified the potential impact on the employment as a result of the full and partial automation of British Columbia ports - Prince Rupert, Delta and Vancouver. The Prism considered two automation scenarios:

- "brownfield" port automation, which upgrades the existing terminal, and

- "greenfield" port automation, which builds new facilities that are more likely to be automated and does not require the conversion and demolition of existing structures.

As a result, it was established that semi-automated terminals reduced the workforce in the "target jobs" by $50 \%$, and fully automated terminals might reduce employment in the same by $90 \%{ }^{7}$. In addition, the report noted that automation had led to a slight increase in the number of labour force engaged in the maintenance and repair but in general the increase could not compensate for the number of redundancies.

Disputes between trade unions and terminal operators over employment have had a catastrophic impact on the local economy and the ports. In the short term, ports have lost their business, i.e. disappointed shippers were diverted to another mode of transport or to other ports, which significantly has increased their costs. An agreement has been followed by excruciating congestion in ports. In the long run, ports must deal with their damaged reputation and must work to restore the confidence in them (Keefe 2020).

It is understandable that not only redundancies but also transformations of jobs take place in the process of automation, whereby the role of man in the port environment changes. Obviously, the skills and the participation of the labor force will also need to be adapted. Future automation is possible, but only if workers are properly qualified to master new technologies. A report by the International Transport Workers' Federation (ITF) states that the transition must be "evolutionary, not revolutionary" and must not exclude those who have worked in the industry throughout their lives. The increasing application of intelligent training and retraining methods, using augmented and virtual reality, to fully prepare workers 
today and tomorrow with the necessary knowledge, skills and expertise for the jobs of the future is fully justified (Donovan 2019).

Risks associated with uncertain increase of productivity

The strong pressure by consumers and mega-ships creates high expectations for ports to handle an increasing amount of cargo. Ports are the main nodes of the supply chain, which are forced to automate their operations in order to handle containers more efficiently.

Container terminals must meet two challenges related to productivity: how to increase traffic per hour and how to reduce the costs per movement.

Despite mega-ships carrying more than 23,000 TEUs, ports must also handle smaller vessels. The volumes of containers that terminals have to handle are dynamic, i.e. large ships do not call at ports daily, which poses to the ports the problem of cost reduction.

In their paper "The Future of Automated Ports", McKinsey state that terminals will seek to reduce the operating costs and increase productivity in order to justify their investment in automation. McKinsey estimate that the operating costs of the automated "greenfield" terminal will need to be about $25 \%$ lower than those of the conventional terminal, or productivity will need to be increased by $30 \%$ and operating costs will need to be decreased by $10 \%$ to be worth investing (Knowler 2018).

The survey in the maritime industry finds that there is a noticeable difference between the expectations of the respondents and the reality. The differences are shown in Table 2.

Table 2. Expected and real values of operating costs and productivity after automation of container terminals

\begin{tabular}{|l|l|l|}
\hline Indicators & Expectations & Reality \\
\hline 1. Operating costs & decrease by $25-55 \%$ & decrease by only $15-35 \%$ \\
\hline 2. Productivity & increase by $10-35 \%$ & decrease by $7-15 \%$ \\
\hline
\end{tabular}

Note: Adapted from (Knowler 2018)

The analysis of the data presented in Table 2 shows that at this stage the decrease of operating costs is less than expected by about $10-20 \%$, and the increase of productivity is less than expected by about $3-20 \%$.

A key productivity indicator that is monitored is the "number of movements per hour" indicator. In fully automated terminals, the average number of movements per hour for the quay cranes is about 20, and in many conventional terminals it is about 30 . With such values of the indicator the automation cannot overcome the burden of initial capital costs. In addition, the reality disproves expectations that productivity will increase with the size of ships and shipments. 
According to the analysis of JOC Port Productivity data, the aggregate value of the indicator "number of movements per hour" has decreased by $4 \%$, which means that ships have had an extra stay of 70,000 hours in ports in the first half of 2018 compared to the first half of 2017 year. After a continuous period of intensive growth, the average size of ships or the number of containers handled per call did not increase in the first half of 2018 compared to the same period in 2017 (Knowler 2018).

The solution of the issues related to productivity is sought in the application of $5 \mathrm{G}$ and wireless communications, which will help ports in their digital transformation. Linking the physical and digital assets of ports will improve "real-time decision making" and will allow them to manage more data (Schwerdtfeger 2020).

Issues related to exception handling

In their paper "The Future of Automated Ports", McKinsey state that more than $60 \%$ of the operators in the study are united around the opinion that when ports have a large number of exceptions, the probable "culprit" is the wrong approach to the automation of manual processes. The reason is that these ports miss an important step: simplifying the processes before automating them. Such processes remain cumbersome even after configuration by automated systems. Therefore, the terminals cannot afford to focus only on the ideal container handling option. They need to be sure that they can handle situations where something does not work according to expectations. In automated terminals, there is no way to switch to manual control, thus this problem must be paid attention during service, testing and training. The automated terminal reaches its highest productivity, if exception handling is properly combined with the right set of staff skills. Paradoxically, terminal automation evolves through enhancement and the need for operator intervention decreases, while the average complexity of exceptions that need to be handled automatically increases. This means that operators need to be better trained to perceive and understand the automated system as a whole. Emulation-based exception handling can help operators play a wide range of scenarios and prepare for the difficult task to operate an automated container terminal (Keskinen et al. 2017; Knowler 2018).

\section{Conclusions}

Despite the difficulties faced by terminal operators, the belief in the sector is that advanced automation is the way to the safest, cleanest and most accessible future for the complex operating environment of container terminals. Despite the high degree of automation, man retains his central place, i.e. the interaction between science, systems engineering, design, simulation and production operations is unthinkable without the "human touch".

In view of the above issues and for mastering the new technologies $(5 \mathrm{G}$, Internet of things, Blockchain, etc.) applied in the automated container terminals, the following conclusions are made: 
1. It is necessary to maintain close cooperation between automated equipment manufacturers, software developers and users (terminal operators, logistics operators, carriers) in order to identify deficiencies and to ensure the smooth flow of information;

2. It is necessary to monitor, analyze and manage the operation of automated container terminals by applying second generation efficiency assessment methods (e.g DEA);

3. Future port specialists must be qualified to work with engineering business processes and systems integration. Their preparation should include "digital twin" and "virtual reality" technologies, which would help to improve the simulation experience and the skills to manage the real processes taking place in the automated container terminals.

\section{NOTES}

1. A PEMA Information Paper. Container Terminal Automation. https://www. pema.org/wp-content/uploads/downloads/2016/06/PEMA-IP12-ContainerTerminal-Automation.pdf

2. Everything You Need to Know About Port Automation, 27th Mar 2018, Safe seas, safe shores. //SHM SHipcare. https://www.shmgroup.com/blog/everythingneed-know-port-automation/ Accessed at: April 2020.

3. Atlas logistics network, Moody's forecasts more automated container terminals.10.07.2019. Available at: https://atlas-network.com/moodysforecasts-more-automated-container-terminals/. Accessed at: April 2021

4. Fully and Semi Automated Container Terminals, Total Hectares, 2019. Available at: https://porteconomicsmanagement.org/?page_id=979. Accessed at: April 2021.

5. The future of automation at terminals and ports. 9 Oct 2018. Available at: https:// www.icontainers.com/us/2018/10/09/the-future-of-automation-at-terminalsand-ports/. Accessed at: March 2021.

6. The Maritime Executive Intellectual Capital for Leaders, 09 July 2020. Available from: https://www.maritime-executive.com/article/moody-s-port-automationmay-not-always-deliver-results. Accessed at: March 2021.

7. Port News: The Fallout From Container Port Automation, 16 September 2019. //Hellenic Shipping News Worldwide Online Daily Newspaper on Hellenic and International Shipping. Available at: https://www.hellenicshippingnews.com/ the-fallout-from-container-port-automation/, Accessed at: March 2020.

\section{REFERENCES}

Chu, F., Gailus, S., Liu, L., NI, L., 2018. Article. The future of automated ports. McKinsey\&Company: Travel, Logistics \& Transport Infrastructure, 4 December, 2018. Available from: https:// www.mckinsey.com/industries/travel-logistics-and-transportinfrastructure/our-insights/the-future-of-automated-ports. Accessed at: June 2020. 
Donovan, L., 2019. Insight: How Will Automation Change the Workforce? Port Technology. 25 March 2019. Available from: https:/www.porttechnology. org/news/insight_how_will_automation_change_the_workforce/. Accessed at: April 2021.

Kaunonen, A., Kalmar, 2018. Port operators need to demand standardisation in container terminal automation. [29 May 2018]. Available at: https://www. kalmarglobal.com/news--insights/articles/2018/20180529 port-operatorsneed-to-demand-standardisation-in-container-terminal-automation/, Accessed at: April 2021.

Keefe, H., P., 2020. Port Automation Puts Labor on Notice. Available at: https:// www.maritimeprofessional.com/magazine/story/201509/automation-labornotice-499999, Accessed at: June 2020.

Keskinen, A., Annala, IL., Miedema, P., 2017. Maintenance of automated terminals. KALMAR, 12. [March 2017]

Knowler, G., 2018. Costs found to outweigh port automation benefits. [13 December 2018\}. Available at: https://www.joc.com/technology/costsfound-outweigh-port-automation-benefits_20181213.html. Accessed at: June 2020.

Saanen, Y., 2020. Why port automation fails [April 2020]. TBA Group, Delft, the Netherlands. Available at: https:/www.tba.group/company-info/newssection/256/why-port-automation-fails/, Accessed at: June 2020.

Schwerdtfeger, M., 2020. PTI Webinar: How can 5G accelerate port digitalisation? Port Technology 12 [June 2020]. Available at: https:// www.porttechnology.org/news/pti-webinar-how-can-5g-accelerate-portdigitalisation/. Accessed at: February 2021.

Schwerdtfeger, M., 2020. What is the future of automation?, Automation and Optimization. Port Technology 13 [Online, February 2020]. Available from: https:/www.porttechnology.org/news/what-is-the-future-of-automation/. Accessed at: February 2021.

Shen, C., 2019. Lack of standardisation hampering port automation. Ports \& Container Shipping 18 [July 2019] Available from: https://informaconnect. com/lack-of-standardisation-hampering-port-automation/. Accessed at: April 2021.

\author{
Yana Gancheva \\ https://orcid.org/0000-0001-7615-1460 \\ Nikola Vaptsarov Naval Academy \\ Varna, Buulgaria \\ E-mail: y.gancheva@naval-acad.bg
}

